\title{
Trade and Manufacturing in Sub-Saharan Africa
}

\section{A. Désiré Adom}

\section{Eastern Illinois University}

\begin{abstract}
Trade and manufacturing have gained momentum in economic debates across Africa as of late. In particular, this study attempts to shed light on the impact of trade openness on manufacturing in Sub-Saharan Africa (SSA). Using a dual comparative approach made of vector auto-regression (VAR) and general method of moments (GMM) applied to 36 countries, results indicate that trade openness impedes the development of manufacturing. The negative effect of trade openness, which remains very limited in scope notwithstanding, underscores an essential feature regarding the entire manufacturing sector in SSA. Indeed, the idiosyncrasies of this sector - namely, underdevelopment, nascent industries and lack of diversification, among others - severely undermine the resilience of countries in SSA as they face heightened international competition.
\end{abstract}

Keywords: Trade openness, Manufacturing, Sub-Sahara Africa, Vector auto regression.

JEL Classification: $F 14, F 41, F 60$

Article Received: 03 April 2020

Revised: 14 April 2020

Accepted: 27 April 2020

\section{Introduction}

The paramount role of trade for a sustained development process in any country cannot be overstated. It is a stylized fact that, from the Greek hegemon to the British empire in the $19^{\text {th }}$ century, trade was at the epicenter and the hallmark of economic development and power projection. In the $20^{\text {th }}$ century, the rise of both the United States and ultimately Japan was underpinned by their unsurpassed abilities to engage in trade with the rest of world. Through this channel, they displayed and shared with the world American and Japanese know-how and ingenuity. In the $21^{\text {st }}$ century, the meteoric ascension of China from a predominantly rural country a short few decades earlier to an economic powerhouse has likewise been fueled by trade.

For decades, Africa has lagged other regions of the globe, namely, North America, Europe Asia and Latin America, as far as trade is concerned. This is observed on a dual count of international and intra-regional trade. According to figures by the United Nations Conference on Trade and Development (UNCTAD), the African region barely accounted for $2.80 \%, 3.26$ and $2.70 \%$ percent of global trade in 1990, 2010, and 2018, respectively (See Figure 1). Moreover, the African Union (AU) points out that the continent's share of intra-regional trade remains relatively meager at $13 \%$ compared to $60 \%, 40 \%$, and $30 \%$ for Europe, North America and ASEAN, respectively [1]. To address these weak performances, African decision-makers recently embarked on an ambitious continent-wide free trade area known as the African Continental Free Trade Area (AfCFTA) in 2018. The treaty creating the AfCFTA was signed in Kigali, Rwanda, by approximately 52 of the continent's 55 countries under the auspices of the AU. And, it is slated to come into force in $2019^{1}$. Once ratified by all countries, it will cover a formidable economic zone of more than 1.2 billion people with a combined GDP in excess of US\$2 trillion.

It is well-documented that the African continent abounds in natural resources and boasts a mostly clement climate along with rich and fertile soils that are propitious to a wide range of crops consumed worldwide. On the one hand, the bulk of these resources and crops are traded in a raw state. This

\footnotetext{
${ }^{1}$ It should be noted that 51 countries signed the treaty in 2018. The $52^{\text {nd }}$ country, Zambia, did it on February 10, 2019. There were still three countries - Benin, Eritrea, and Nigeria - that had not signed the treaty on that day. As of June 5, 2019, 24 countries had ratified it.
} 
situation is due to a persistent lack of processing capacities both quantitatively and qualitatively. On the other hand, one cannot overlook the fact that this same situation is part of a bigger picture of systemic weakness throughout the continent's manufacturing industry. From 1995 to 2018, Africa's total exports averaged about US $\$ 337$ billion per annum. Over the same period, unprocessed and raw materials topped on average a massive US $\$ 265$ billion, which is about $79 \%$ of this total ${ }^{2}$.

As shown in Figure 2, actual figures hover between $70 \%$ and $84 \%$. A reduction of that share, by generating more value-added, can markedly raise the level of revenue for Africans. It can only be achieved by means of a developed and diversified manufacturing sector. With the continent being on the lower end of the knowledge curve, trade can be an effective vehicle to acquire much needed expertise and technology as well as speed up their horizontal and vertical disseminations across the board. Such a course of action accentuates the need for a closer look at the link between manufacturing and trade, while lending credence to the relevance of this investigation. More specifically, the present research work endeavors to assess the relationship between manufacturing and trade openness. It examines whether the development of the manufacturing sector in Sub-Saharan Africa (SSA) can be spurred by trade in general and trade openness in particular.

Paraphrasing Rodrik [2], one may ask, can trade openness help Africa cease to be synonymous of manufacturing failure? This project sets out to explore some elements of answers with a comparative methodology integrating two well-established tools in the literature that have been highly effective in both empirical and theoretical research works - namely, the vector auto regression (VAR) and the general method of moment (GMM). The former has been used in many seminal studies that have yielded strong, verifiable and far-reaching results. The latter can be extremely powerful when, among other things, a clear functional form to

\footnotetext{
${ }^{2}$ For unprocessed and raw materials, this study uses the United Nations' Standard International

Trade Classification (SITC) classification. That is, SITC $(0+$ $1+2+3+4+68+667+971)$.
}

describe the relationship between variables cannot be established or is not perceivable.

This research bears two singularities that impart value to the literature. First, the comparative approach involved furthers our understanding of the impacts of trade openness on manufacturing with developing countries in Africa. Second, the sheer number of countries considered in this analysis, 36, provides, to the best of our knowledge, the most comprehensive platform for exploring this subject on the African continent.

The paper revolves around five parts. The next part focuses on the review of literature to highlight notable studies pertaining to trade, trade openness, and manufacturing in Sub-Saharan Africa. A methodology discussing key features of estimation techniques is surveyed in the third part along with a presentation of data. Results and policy implications of findings are debated in the fourth part. At last, concluding comments are shared in part 5 .

\section{Literature Review}

The state of Africa's manufacturing sector has drawn renewed interest from local stakeholders and beyond as of late. In point of fact, there is a growing sense from African scholars and politicians that this sector has been overlooked to a considerable extent in both long- and short-term development programs. In that respect, Golub et. al [3] touch upon an insightful question asking whether Africa can compete with China in manufacturing. They address the question through the prism of relative unit labor costs (RULC) by comparing unit labor costs in both Sub-Saharan Africa (SSA) and China. Findings expose a daunting task for the former in any competition with China although there are signs that SSA's competitiveness has improved in recent years. Moreover, they argue that African countries should attempt to rebase their respective economy and exports. Authors suggest that these countries can achieve this milestone by further focusing on laborintensive exports in other sectors. They view this approach as the most viable for SSA countries to experience progress in exports and gain notable ground.

Moyo [4] looks at the nexus between manufacturing exports and infrastructure quality at the micro level using data from 
firms in 10 African countries. With probit and tobit regression models, it is uncovered that poor quality of infrastructure, namely, customs, transportation, electricity and water, are detrimental to countries' export efforts and their ability to engage in trade.

Legitimate interrogations continue to arise with respect to trade between Africa and China. China has indeed scored a position as one of Africa's major trading partners. There have however been growing apprehensions concerning this position, which could slow down or stifle altogether progress in the continent's manufacturing sector. Elu and Price [5] have attempted to figure out if trade with China involves transfer of productivityenhancing technology from this country to Africa. Towards that objective, they posit a dynamic production function for Africa and derive the total factor productivity (TFP) in the form of a Solow residual for a typical firm. A parameterization schedule is devised, and it is followed by estimations using ordinary least squares (OLS) and general method of moments (GMM). They find that increased trade openness of SSA countries does not result in a transfer of technology that boosts firms' productivity. In other words, more trade with China is prejudicial to SSA firms.

The location of firms or participants always plays an important role in affecting trade density. Naude and Matthee [6] reckon with South Africa to analyze the geographical location of manufacturing exports of many industries. The methodological tools considered involve piecewise and continuous polynomials to assess a density-distance relationship. According to their results, there is evidence of substantial concentration in manufacturing production in the country. Point in fact, 84 percent of total manufacturing exports is produced in only 6 percent of magisterial district. They find also that most of manufacturing exports are executed by firms located within $100 \mathrm{~km}$ of an export hub reaching as high as 98 percent for electronics. Employment remains a fundamental point of discussion when talking about trade among countries. It oftentimes draws passion. Some scholars, such as Jenkins and Sen [7], have scrutinized the impacts of international trade on employment in an economy. Their study contemplates four developing economies, namely, Bangladesh, Kenya, South Africa and Vietnam. Findings interestingly show that the behavior of employment was not uniform across developing countries from Asia and Africa. Closer integration to global economy through international trade has a negative effect on employment in Kenya and likely in South Africa. On the other hand, it positively affects employment in Bangladesh and Vietnam. These outcomes are determined using a three-pronged methodological approach based on factor content, growth accounting, and labor demand.

\section{Methodology and Data}

\section{Methodology}

This paper contemplates a comparative approach built upon two estimation techniques, namely, the vector auto regression (VAR) and the general method of moment (GMM). Both were introduced in the literature in the 1980s, by Sims [8] and Hansen [9], respectively. To understand the relationship between manufacturing and trade openness, a model including two sets of covariates is defined: economic (EC) and foreign (FOR). Economic factors typically account for domestic characteristics of each economy considered. Four of such factors are deemed critical in this empirical analysis.

They are (i) lagged output (OUT), (ii) inflation (INF), (iii) investment (INV), and (iv) government spending (GOVCS). The inclusion of foreign factors is an acknowledgment of the fact that no country is impervious to dynamics in international markets. Trade openness is accordingly relevant in this category. Moreover, a measure of exchange rate volatility is considered with a two-currency index comprising the US dollar and the Euro, the two largest reserve currencies in the world ${ }^{3}$. Based on the discussion above, a preliminary form of the model is as follows:

$$
\mathrm{Man}=\mathrm{f}(\mathrm{EC}, \mathrm{FOR})
$$

In practice, a more useful formulation is described below:

$$
\begin{gathered}
\mathrm{Man}_{\mathrm{t}}=B_{0}+B_{1} \mathrm{OUT}_{\mathrm{t}-1}+B_{2} \mathrm{INV}_{\mathrm{t}}+B_{3} \mathrm{GOVCS}_{\mathrm{t}}+ \\
B_{4} \mathrm{INF}_{\mathrm{t}}+B_{5} \mathrm{TROP}_{\mathrm{t}}+B_{6} \mathrm{FXVOL}_{\mathrm{t}}+\varepsilon_{\mathrm{t}}
\end{gathered}
$$

\footnotetext{
${ }^{3}$ The weight of each currency is determined by the country's share of global output.
} 
Three other variants of equation (2) are formulated to not only capture the relationship between manufacturing and trade openness, but also assess its robustness. It's noteworthy that the robustness check is conducted another way through a secondary estimation method, the GMM. The first estimation method applies a VAR. It's been abundantly used across the literature, and it encompasses a set of autoregressive lagged distributed equations conveniently arranged in a matrix form:

$$
\begin{aligned}
\mathrm{Z}_{\mathrm{t}}= & \Omega_{1} \mathrm{Z}_{\mathrm{t}-1}+\Omega_{2} \mathrm{Z}_{\mathrm{t}-2}+\Omega_{3} \mathrm{Z}_{\mathrm{t}-3}+\ldots+\Omega_{\mathrm{k}} \mathrm{Z}_{\mathrm{t}-\mathrm{k}} \\
& +\chi_{\mathrm{t}}
\end{aligned}
$$

$\mathrm{Z}_{\mathrm{t}}$ is a vector comprising all seven variables included in equation (2). Subscript $\mathrm{k}$ is the order of the VAR as empirically determined to be appropriate ${ }^{4}$. $\Omega$ is a matrix of coefficients. A search for a long-run relation is determined through co-integration using equation (3). A long-run relationship exists if the residuals $\chi$ are found to be stationary.

In a second method, equation (2) is reassessed with GMM. Beside the fact that the GMM procedure is built around minimal assumptions, it presents two chief advantages. For one, it can both accommodate a variety of relationships among variables, whether linear or nonlinear, and yield consistent estimates. Furthermore, even with limited knowledge about the probability distribution function of data, GMM are able to generate robust results.

\section{Data}

Two main sources are taken into consideration: The World Development Indicators (WDI) [10] from The World Bank Group, and the United Nations Conference on Trade and Development Statistics (UNCTADStat) [11]. Seven time-series proxying all variables are collected, and they span 29 years, from 1980 to 2018. Changes in the manufacturing sector are entered using data on value-added as a percentage of gross domestic product (MANVAPGDP). Output iscovered by gross domestic product in constant United States dollar (RGDP), while investment is accounted for with gross fixed capital formation as a share of gross domestic product (GFCFPGDP). Data on government spending are readily available and are in real terms (GOVCS). Data on consumer price index (CPI) serve as the basis to assess inflation. Trade openness (TROP) is the sum of imports and exports expressed as a percentage of GDP. At last, foreign exchange volatility (FXVI) is measured by a weighted average of the two most important currency reserves, namely, the US\$ and the Euro.

\section{Results and Policy Implications}

\section{Results}

In the first of three steps, summary statistics and a correlation matrix are derived. This study consists of 1,014 observations per variable as a common sample. Table 1 reports means, medians, maxima, minima, standard deviations, and observation counts of series. The pair-wise correlation matrix is available in Table 2. Of all correlation coefficients, the one between RGDP and GOVCS in particular could be a cause for empirical concern as it tops 0.93 .

To check the stationarity of variables used in the model, a dual approach using common and individual unit root tests is in order in the second step. On balance, five separate tests are conducted, comprising two for common unit roots and three for individual unit roots. As shown in Table 3, all tests suggest stationary in level for variables. Significance levels oscillate between 0 and 5 $\%{ }^{5}$.

At last, two sets of estimations are run and outlined. To eliminate spuriousness and ascertain consistent outcomes, four variants of the baseline model are derived from the outset. Then, by reason of the finding reported in Table 2 regarding a high positive correlation between two variables of the baseline model, the four variants abovementioned are reassessed with the introduction of an interactive term to help mitigate any potential endogeneity issues.

\footnotetext{
${ }^{4}$ The orders of vectors $Z, \Omega$, and $\chi$ are $7 \times 1,7 \times 7$, and $7 \times 1$, respectively.
}

${ }^{5}$ It is precisely $3.6 \%$. 
Tables 4 and 5 document results that appear uniform across specifications for RGDP, FXVI, and CPI, and they turn up significant for the most part. The positive impact of output on manufacturing in these countries is in line with expectations. A growing economy fosters an expansion in the share of manufacturing out of total output. Concretely speaking, for every percentage increase in output, a 0.01 to 0.12 percentage points rise in manufacturing as a percentage of output is to be expected. This expansion is relatively modest even in the best-case scenario.

With respect to volatility on foreign markets, it unchangingly comes out that an increase in volatility leads to an increase in manufacturing share of GDP in Sub-Saharan African countries (SSAC). This finding strikes as counterintuitive at first. However, there could be some viable economic rationales behind it in SSAC. Case in point, it is a statistical fact that most of these countries heavily rely on proceeds from sales of raw materials. Sustained instability on world markets may expedite both the development and implementation of policies destined to promoting domestic transformations of raw materials in an attempt to climb up the ladder of valueadded.

This is not to suggest that the pursuit of such policies is novel across SSA per se, but it further accentuates the urgency of developing and implementing them more vigorously. It tackles the need to shield their main source of income, while fostering the creation of a strong manufacturing sector, which ultimately engenders economy-wide positive externalities. The positive relationship between inflation and the share of manufacturing matches expectations as higher prices increase incentives for productive activities and expansions of existing plants.

Economic theory supports the positive relationship between investment in a country and the development of manufacturing. The improvement of a country's infrastructure through formation of fixed capital reduces production costs and props up prospective profits and business optimism. This applies to many types of businesses, but it is even more so in manufacturing considering that businesses in this sector typically incur substantial start-up and operating costs relatively to others in the non-manufacturing sector, like services. This study uncovers mostly a positive and significant relationship across variants, especially when high correlations in the model are controlled ${ }^{6}$. It is anticipated that the boost to the share of manufacturing in total output ranges, on average, from a low of 0.02 percentage points to a high of about 0.25 percentage points. Similarly, empirical results detect that government consumption is significant and props up manufacturing in SSAC. Indeed, with a relatively small private sector due to the combination of challenging business environments and high poverty rates, the government stands in most cases as the primary client of the manufacturing sector. Thus, stimulating government consumption directly and indirectly, through income and multiplicative effects, bolsters the manufacturing sector. In this research work, the impact is found to be relatively modest with every percentage increase in government consumption, which could raise the share of the manufacturing sector by as much as 0.16 percentage points.

The interaction between trade openness and manufacturing is the crux of this investigation. The impact of trade openness comes out significant and negative across many variants of the model when potential endogeneity issues are taken into consideration. There is only one exception however where the specification fails to be significant. In other words, increased trade openness slows down growth in the share of manufacturing out of total output over time or curtails it altogether. It should be noted that none of the coefficients turn out significant when potential endogeneity problems are overlooked. There is no ironclad economic theory purporting a one-sided or predetermined direction for the impact of trade openness on manufacturing. As a matter of fact, trade openness can act as a blessing for an economy by giving rise to lots of economic opportunities for domestic economic agents. It can equally act as a curse in some instances. In the former case,

\footnotetext{
${ }^{6}$ There is only one negative sign, and it comes out as insignificant.
} 
consumers can be beneficiaries of a favorable cost to quality ratio, and producers as well can reap gains from technology transfers and sometimes inexpensive inputs. In the latter scenario, when the country's manufacturing sector is not sufficiently established or prepared to face international competition - due for instance to lower foreign prices or better technology or products - it could see its manufacturing base be seriously undermined. In the direst of cases, the entire base could be reduced to its mere expression.

The results of this empirical work corroborate the latter scenario wherein SSAC experience a contraction of their manufacturing sector as a share of total output when they expand their involvement in international trade. This scenario is relevant for these countries in light of the fact that they have an underdeveloped or nascent manufacturing industry. As such, domestic firms in this industry may not be nimble enough to adapt and have a level playing field with their international counterparts mounded with better capabilities and expertise that lead to mass production of price competitive goods. This said, it is found that even under that schema, the slump in manufacturing in SSAC as a share of total output is limited and does not, on average, exceed 0.03 percentage points for every percentage point increase in trade openness.

\section{Policy Implications and Recommendations}

The ramifications of the outcome in this analysis are debate-worthy and give prominence to another set of challenges for SSAC in their ultimate goal of establishing a free trade area spanning the entire continent. There is little to no doubt that such a free trade area would spur a feeble intra-African trade and shore up economic opportunities for consumers, producers, and governments. How then can these countries reconcile their goal with the dragging effect of trade openness upon manufacturing? Manufacturing has received a great deal of attention as countries are trying to create more value-added, and therefore procure more revenue from their abundant natural resources. Sub-Saharan African countries (SSAC) can alleviate, even erase, these dragging effects by pursuing a strategy to build up or strengthen their manufacturing industry. As a matter of fact, the manufacturing sector in SSAC suffers from a variety of issues from restricted access to financial markets for domestic firms to lowskilled human capital and red tapes, which severely encumber its development. Governments should heighten efforts aimed at broadening and deepening financial markets. Specific policies focusing on existing manufacturing firms and attracting new ones should be in order. These could range from tax incentives to governmentfunded programs to target particular sectors where countries have comparative advantages. Furthermore, the government could actively act as a steward of the industrialization process by helping build from the ground up firms or factories, as strategically determined and needed. As an illustration of this point, let's consider a country that is a large producer of a particular raw material, say cocoa or cotton. This country should accordingly design such government-funded programs to prop up local transformation of cocoa or cotton by setting up factories. Once operational and soundly managed, the government could fully or partially transfer its shares to private entities. Alternatively, a government could completely concede the operations and management of such firms to hired private cabinets or parties at the very start. This approach was successfully applied in Asia and Europe throughout the post-world war II era. One should not understate the relevance of human capital to bring such ventures to fruition. If not properly addressed, it could be a dealbreaker. Governments in SSAC could address this pitfall by contemplating competences from across the globe.

\section{Conclusion}

The nexus between manufacturing and 
trade has never been as important for SubSaharan African countries (SSAC) as today with the enactment of the African Continental Free Trade Area (AfCFTA). This empirical work has revealed that trade openness in SSAC hampers, although in a limited fashion, the expansion of manufacturing's share in total output. The economic rationale behind this outcome is that an underdeveloped or nascent manufacturing sector may not be resilient enough to withstand intense international competition from foreign partners in Asia

\section{References}

1. African Union. Available at https://au.int/en/ti/biat/about.

2. Rodrik D (2018) "Straight Talk on Trade", 79, Princeton University Press. Princeton, New Jersey. United States of America.

3. Golub SS, Ceglowski J, Mbaye AA, Prasad V (2018) "Can Africa compete with China in manufacturing? The role of relative unit labour costs," The World Economy, 41(6):1508-1528. DOI: 10.1111/twec. 12603

4. Moyo B (2012) "Infrastructure Quality and Manufacturing Exports in Africa: A FirmLevel Analysis," South African Journal of Economics (SAJE), 80(3):367-386.

5. Elu JU, Price GN (2010) "Does China Transfer Productivity Enhancing Technology to Sub-Saharan Africa? Evidence from Manufacturing Firms," African Development Review, 22(1):587598. and Europe. Therefore, an appropriate course of action for these countries would be to pursue critical structural and institutional changes to strengthen the manufacturing industry. In that manner, it will be able to gain innimbleness and competitiveness. A comparable study focusing on North African countries would be a natural complement to this study in order to bring about a comprehensive understanding of the impact of trade openness on the manufacturing sector across the entire African continent. $\mathrm{n}$

6. Naudé W, Matthee M (2010) "The Location of Manufacturing Exporters in Africa: Empirical Evidence," African Development Review, 22 (2):276-291.

7. Jenkins R, Sen K (2006) "International Trade and Manufacturing Employment in the South: Four Country Case Studies," Oxford Development Studies, 34(3):299322. DOI: $10.1080 / 13600810600921802$.

8. Sims AC (1980) "Macroeconomics and Reality," Econometrica, 48(1): 1-48.

9. Hansen LP (1982) "Large Sample Properties of Generalized Method of Moments Estimators," Econometrica, 50(4): 1029-1054. doi:10.2307/1912775

10. World Development Indicators (WDI). World Bank Group, Washington, D.C.

11. United Nations Conference on Trade and Development Statistics (UNCTADStat). United Nations system, New York City, New York.

Table 1: Summary statistics

\begin{tabular}{|c|c|c|c|c|c|c|c|}
\multicolumn{1}{c|}{} & MANVAPGDP & RGDP & GFCFPGDP & & & & \\
\hline Mean & 11.8833 & $2.87 \mathrm{E}+10$ & 19.48 & $2.84 \mathrm{E}+10$ & 69.3694 & 65.3957 & 142.07 \\
\hline Median & 11.0882 & $9.66 \mathrm{E}+09$ & 18.928 & $9.31 \mathrm{E}+08$ & 57.6408 & 57.9145 & 143.17 \\
\hline Maximum & 30.936 & $4.29 \mathrm{E}+11$ & 68.1224 & $1.72 \mathrm{E}+12$ & 481.985 & 225.023 & 193.13 \\
\hline Minimum & 0.7157 & $3.45 \mathrm{E}+10$ & 0.0019 & 12055277 & $4.11 \mathrm{E}-04$ & 2.8673 & 100.08 \\
\hline Std. Dev. & 5.542 & $6.63 \mathrm{E}+10$ & 8.66 & $1.63 \mathrm{E}+09$ & 58.6689 & 34.7089 & 18.95 \\
\hline Observations & 1014 & 1014 & 1014 & 1014 & 1014 & 1014 & 1014 \\
\hline
\end{tabular}


Table 2: Correlation matrix

\begin{tabular}{|c|c|c|c|c|c|c|c|}
\cline { 2 - 8 } \multicolumn{1}{c|}{} & MANVAPGDP & RGDP & GFCFPGDP & GOVCS & CPI & TROP & FXVI \\
\hline MANVAPGDP & 1 & & & & & & \\
\hline RGDP & 0.3367 & 1 & & & & & \\
\hline GFCFPGDP & 0.3227 & -0.1573 & 1 & & & & \\
\hline GOVCS & 0.467 & 0.933 & 0.0389 & 1 & & & \\
\hline CPI & -0.0043 & 0.3742 & -0.0249 & 0.3837 & 1 & & \\
\hline TROP & -0.1727 & -0.4482 & 0.0755 & -0.4279 & 0.3759 & 1 & \\
\hline FXVI & -0.0674 & -0.03863 & 0.0648 & -0.4201 & -0.5332 & -0.2832 & 1 \\
\hline
\end{tabular}

Table 3: Unit root tests

\begin{tabular}{|c|c|c|c|}
\cline { 2 - 4 } \multicolumn{1}{c|}{} & Common roots & Statistic & $\mathrm{p}$-value \\
\hline Test 1 & Levin, Lin \& Chu (t-test) & -1.7997 & 0.036 \\
\hline Test 2 & Breitung (t-stat) & -5.2328 & 0 \\
\hline \hline & Individual roots & Statistic & p-value \\
\hline Test 3 & Im, Pesaran, and Shin (W-stat) & -4.4409 & 0 \\
\hline Test 4 & ADF-Fisher (Chi-Square) & 49.3642 & 0 \\
\cline { 2 - 4 } & ADF- Choi (Z-stat) & -4.416 & 0 \\
\hline \multirow{2}{*}{ Test 5 } & PP - Fisher (Chi-Square) & 46.9442 & 0.0001 \\
\cline { 2 - 4 } & PP - Choi (Z-stat) & -4.354 & 0 \\
\hline
\end{tabular}

Table 4: Estimation results (VAR, dependent: MANVAPGDP) ${ }^{7}$

\begin{tabular}{|c|c|c|c|c|c|c|c|c|}
\hline & I & $\mathbf{I}^{\prime}$ & II & II' & III & III' & IV & IV' \\
\hline RGDP & $1.1845^{* * *}$ & $7.1905 * * *$ & 1.3679 & $3.6122^{*}$ & $1.7379^{*}$ & $10.4268^{* * *}$ & $0.5549^{*}$ & $12.4376^{* * *}$ \\
\hline GFCFPGDP & -0.1064 & $0.1^{*}$ & 0.1685 & 0.021 & 0.0649 & $0.0773^{*}$ & $0.1706^{* * *}$ & $0.251^{* * *}$ \\
\hline GOVCS & 0.6838 & $9.534^{* * *}$ & $0.6688^{* * *}$ & 4.3886 & -0.048 & $11.9173^{* *}$ & 0.2465 & $16.321^{*}$ \\
\hline TROP & 0.0113 & $-0.0304 * *$ & 0.0092 & $-0.0282^{* *}$ & 0.003 & -0.0116 & -0.085 & $-0.0264^{* *}$ \\
\hline CPI & & & $0.2071^{*}$ & $0.1508^{*}$ & $* * * 0.7943$ & $0.8739 * * *$ & & \\
\hline FXVI & & & & & $* 0.4539$ & $0.4696^{* *}$ & $0.2152^{*}$ & 0.2512 \\
\hline RGDP*GOVCS & & $-0.3947 * * *$ & & $-0.1938^{* *}$ & & $-0.4805^{*}$ & & $-0.6562^{*}$ \\
\hline $\mathrm{C}$ & 16.6923 & -162.8809 & -3.9478 & -69.0456 & -95.5381 & -316.0798 & -29.585 & -338.1911 \\
\hline $\mathrm{N}$ & 1,012 & 1,012 & 1,012 & 1,012 & 1,012 & 1,012 & 1,012 & 1,012 \\
\hline Adj. R-square & 0.3191 & 0.3865 & 0.3811 & 0.4046 & 0.4741 & 0.5081 & 0.4994 & 0.5381 \\
\hline F-stat & 49.788 & 212.6826 & 51.194 & 225.5549 & 147.33 & 124.5589 & 177.3061 & 153.7869 \\
\hline P-value & 0 & 0 & 0 & 0 & 0 & 0 & 0 & 0 \\
\hline
\end{tabular}

Note: *, **, *** indicate significance at the 10, 5, 1\% significance levels, respectively.

Table 5: Estimation results (GMM, dependent: MANVAPGDP) ${ }^{8}$

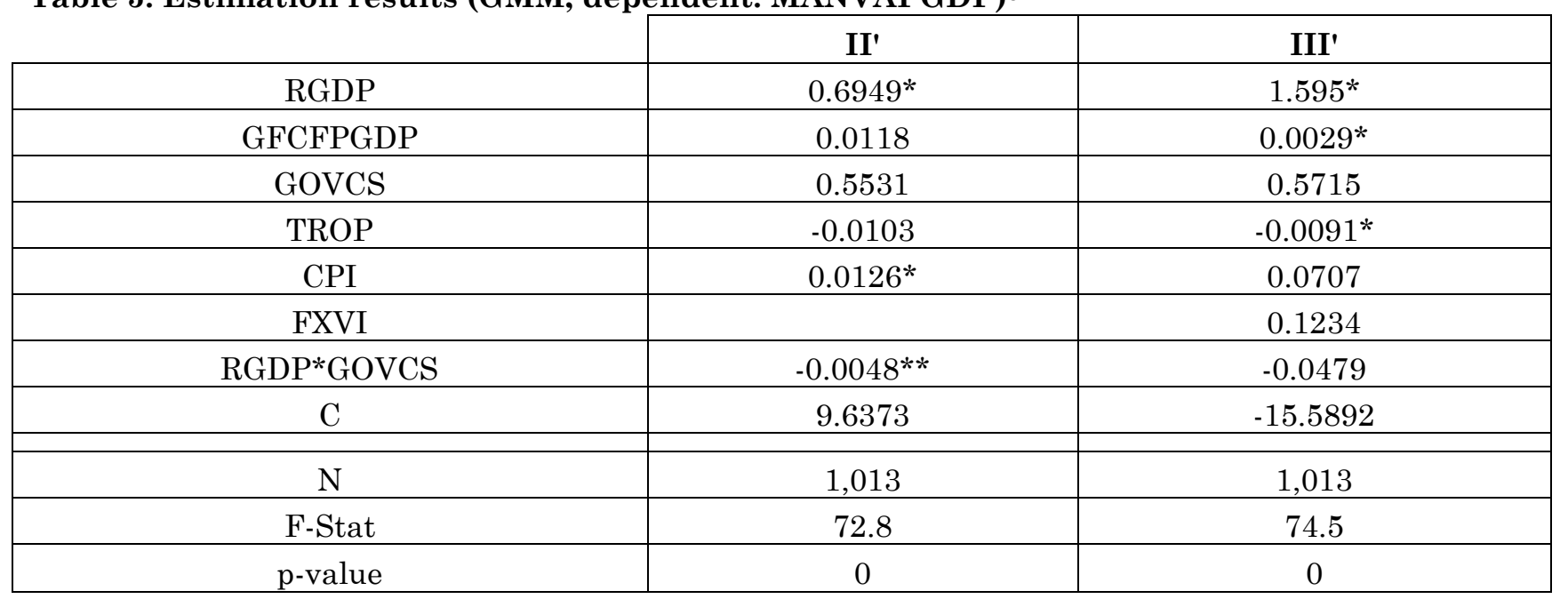

Note: ${ }^{*}, * *,{ }^{* * *}$ indicate significance at the $10,5,1 \%$ significance levels, respectively

\footnotetext{
${ }^{7}$ RGDP, GOVCS and CPI are entered in logarithmic forms.

${ }^{8}$ Moreover, the choice of variants II' and III' was motivated by their inclusiveness with respect to the set of variables considered in the study.
} 


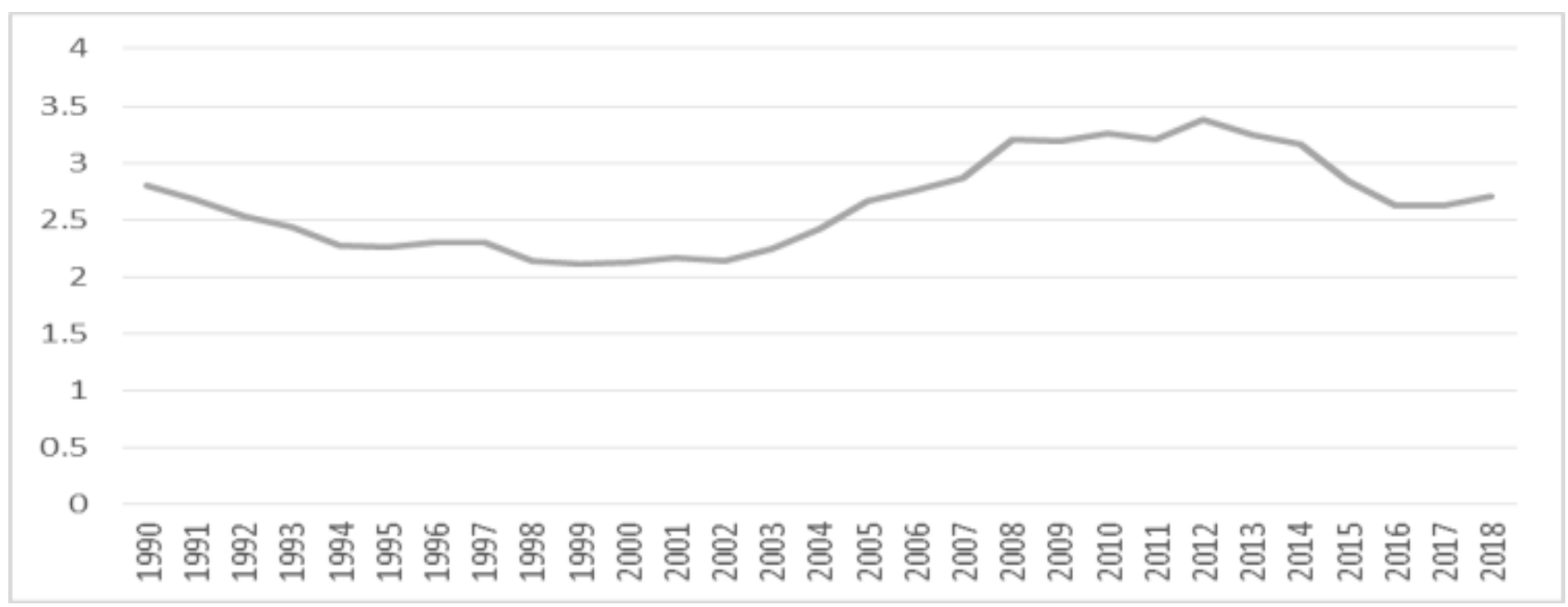

Figure 1: Africa's share of global trade (percentage), 1990-2018

Source: United Nations Conference on Trade and Development Statistics (UNCTAD Statistics)

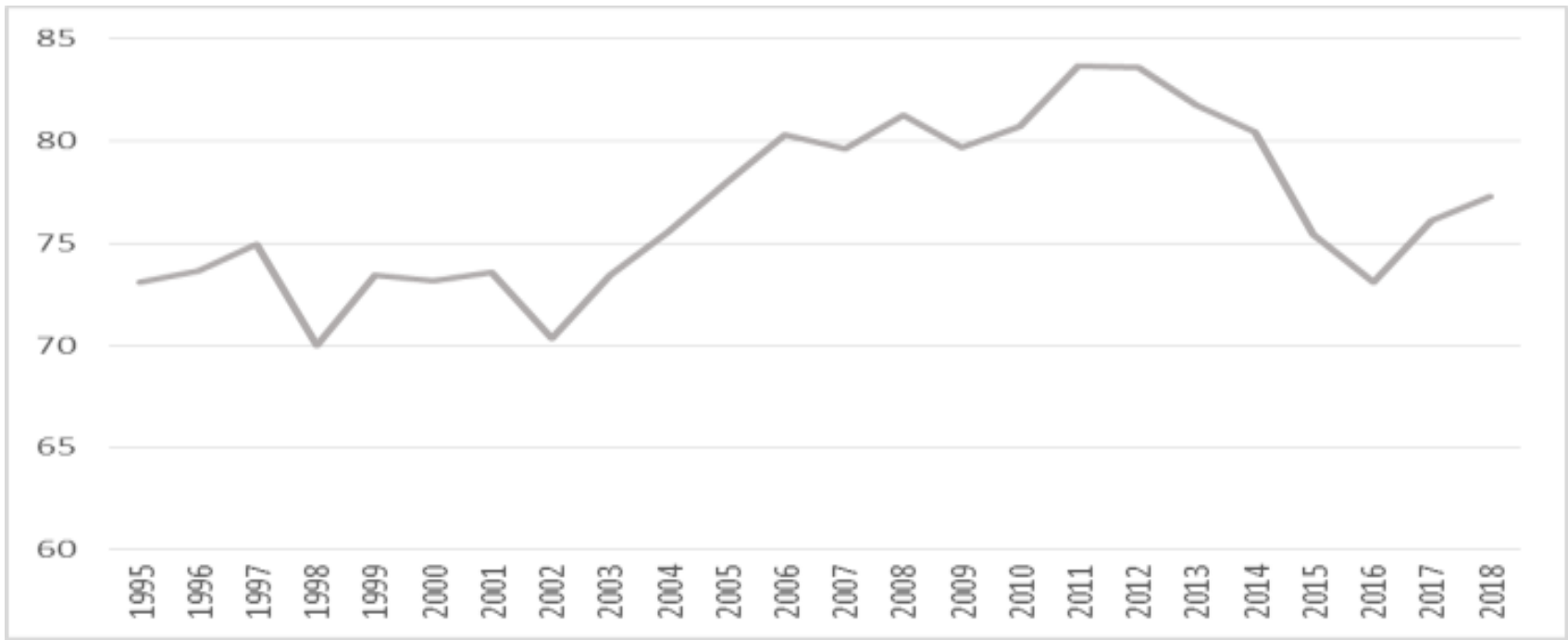

Figure 2: Primary products' share of Africa's total exports (percentage), 1995-2018

Source: Source: United Nations Conference on Trade and Development Statistics (UNCTAD Statistics) 